\title{
Homoclimate of Iceland's meteorological stations for comparison with the homoclimate of some northern countries
}

\author{
Alexander Sadovski ${ }^{1}$ \\ 1 Bulgarian Science Center of the IEAS, Sofia, Bulgaria \\ Maria Ivanova ${ }^{2}$ \\ 2 ISSATPP „N. Poushkarov“, Sofia, Bulgaria \\ Corresponding author: Alexander Sadovski (bsc.ieas@yahoo.com)
}

Academic editor: Aleksandr I. Malov • Received 30 January 2021 • Accepted 17 February 2021 • Published 16 april 2021

Citation: Alexander Sadovski, Maria Ivanova (2020) Homoclimate of Iceland's meteorological stations for comparison with the homoclimate of some northern countries 21(1): 8-17 DOI: 10.17238/issn2227-6572.2021.21.1.8

\begin{abstract}
In many fields including agroclimatology, pedology, plant introduction, environmental health and agricultural transfer, detection of areas of similar climate is of significant interest. Numerical methods including cluster analysis, similarity measures, and other techniques were used to compare climatic data from Islandian meteorological stations to classify them according to similar homoclimate. Using Euclidean distance and City-block (Manhattan) distance, data from Iceland, Finland, Sweden, Norway, and Alaska state of the USA were analyzed to reveal homoclime. One of the conclusions from the study is that Iceland has a similar climate to Alaska and Norway. Climate change is already affecting agriculture, with effects unevenly distributed across the world. These changes will undoubtedly lead to a reconsideration of the question of allocation of appropriate agricultural crops to given areas and evaluation of bioclimatic resources in territories with similar climate. Results from this study are related to the territory of Iceland, but the approach to classify meteorological stations according to similar homoclimate and reveal homoclime in selected territories is applicable everywhere in the world.
\end{abstract}

\section{Keywords}

climate change; cluster analysis; homoclimate; homoclime; similarity measures

\section{Introduction}

In many fields including agroclimatology, pedology, plant introduction, environmental health and agri-

Copyright Sadovski A, Ivanova M. This is an open access article distributed under the terms of the Creative Commons Attribution License (CC-BY 4.0), which permits unrestricted use, distribution, and reproduction in any medium, provided the original author and source are credited. cultural transfer, detection of areas of similar climate is of significant interest. It helps in solving completely different problems like allocation of appropriate agricultural crops to given areas, evaluation of bioclimat- 
ic resources in connection with genetic status of population on certain locations and the effects of global climate change.

Definition of homoclime (Merriam-Webster): a climatically similar environment; specifically: a region climatically similar to another specified region.

Several authors have carried out comparisons of climate in different parts of the world. The term "homoclime" is used by Prescott (1938) for areas with similar climates (Prescott et al. 1952). Others have used the term "homoclimate" (Meigs 1953). Russell and Moore (1970) give the exact definition of both terms. The term homoclimate refers to two or more stations that possess a similar climate, whereas the term homoclime refers to areas or regions, which possess similar climates. So comparisons are made between meteorological stations and they define homoclimates (Russel 1982). In the case of considering local conditions on confined locations, we are using the term "local homoclimates".

In Bulgaria, intensive studies on the climate and climatic regioning have been carried out regarding global areas as the Balkan Peninsula (Nojarov 2017) and Bulgaria (Stanev et al. 1991). However, no attempt is made to find similarities of different locations in a numerical form. A comparison of the climate in Bulgaria and that of states in the United States was made and the homoclime with the states Washington and North Dakota were found (Sadovski 2019).

A study evaluates temperature and precipitation in Alaska from five reanalyses at monthly and daily time scales for the period 1979-2009 (Lader et al. 2016). Alaska is experiencing effects of global climate change that are due, in large part, to the positive feedback mechanisms associated with polar amplification. The major risk factors include loss of sea ice and glaciers, thawing permafrost, increased wildfires, and ocean acidification.

General statistical Information about Iceland is given in Statistics Iceland (2015) and the booklet Iceland in figures (Guðjónsdóttir 2018). Agriculture production of field crops includes hay, potatoes, cereal grains, tomatoes, cucumbers, and turnips. The climate of Iceland is well characterized by Einarsson (1984). Data from meteorological stations were published by Sigurdsson and Einarson (1979). The climatic data for Iceland used in our study are from the Icelandic Meteorological office (2020).

Climate change is already affecting agriculture, with effects unevenly distributed across the world. Future climate change will likely negatively affect crop production in low latitude countries, while positive trends are evident in some northern regions (Porter et al. 2014). Studies on Projected Impacts for crops and livestock in global regions and sub-regions under future scenarios show that yield impact of wheat, maize and soybean for Europe will be positive in Boreal and Alpine sub-regions (Iglesias et al. 2012, p. 509-512). Peltonen-Sainio says (2012) that the climate change takes northern European crop production into a new era. However, fluctuating weather conditions, meaning large inter- and intra-annual as well as spatial variation, are typical for high latitude agro-ecosystems. Therefore, variable conditions have required hitherto continuous adaptation and measures by farmers to manage production risks.

The development of numerical methods for data analysis and computer technique enables to a considerable degree the studies and search for homoclimates. New multivariate statistical methods allow simultaneous consideration of many meteorological parameters for the assessment of climate at any one location.

\section{Methods}

\section{Homoclimate of Iceland stations}

Numerical methods including cluster analysis, similarity measures, and other techniques were used to compare climatic data from Iceland stations in order to classify them according to similar homoclimate.

Data about climate of Iceland used in the analysis: $\mathrm{t}$ - average temperature

tx - average daily maximum temperature

txx - highest maximum temperature 
tn - average daily minimum temperature tnn - lowest minimum temperature

$\mathrm{r}$ - average precipitation

rx - maximum 24-hr precipitation

d_r $>0.1$ - mean number of days with precipitation

(0.1 $\mathrm{mm}$ or more)

d_r $>=1.0-$ mean number of days with precipitation

(1.0 $\mathrm{mm}$ or more)

$\mathrm{vp}$ - mean vapour pressure

$\mathrm{n}$ - mean cloud cover (oktas) sun - mean bright sunshine durations (hrs)

$\mathrm{p}$ - mean sea level pressure

$\mathrm{px}$ - maximum sea level pressure

pn - minimum sea level pressure

30 years average climatological data (1961-1990) for selected 22 meteorological stations (Iceland Met Office 2020) are presented on Table 1.

Statistical characteristics of the data are given in Table 2.

Table 1. Input data for analysis

\begin{tabular}{|c|c|c|c|c|c|c|c|c|}
\hline \multirow{2}{*}{ Stationid } & \multicolumn{6}{|c|}{ Component } & \multirow[b]{2}{*}{ d_r $>=1,0$} & \multirow[b]{2}{*}{$\mathbf{n}$} \\
\hline & $t$ & txx & tnn & $\mathbf{r}$ & $\mathbf{r x}$ & d_r $>0$ & & \\
\hline 1 & 4.3 & 24.3 & -19.7 & 798.8 & 48.2 & 221.2 & 148.3 & 5.8 \\
\hline 178 & 3.5 & 21.0 & -19.0 & 704.6 & 56.6 & 181.8 & 132.4 & 6.2 \\
\hline 188 & 3.2 & 23.5 & -20.5 & 643.1 & 64.4 & 187.0 & 114.2 & 6.1 \\
\hline 220 & 3.7 & 23.2 & -17.6 & 942.9 & 106.4 & 196.5 & 146.9 & 6.3 \\
\hline 250 & 3.1 & 22.5 & -18.4 & 1215.4 & 91.8 & 245.3 & 181.6 & 6.4 \\
\hline 285 & 2.1 & 20.2 & -21.9 & 1136.6 & 87.8 & 259.7 & 171.1 & 6.7 \\
\hline 366 & 2.4 & -22.5 & 25.0 & 469.4 & 45.8 & 171.0 & 116.8 & 6.5 \\
\hline 422 & 3.2 & 20.9 & -23.0 & 489.5 & 42.3 & 170.8 & 102.5 & 6.1 \\
\hline 452 & 2.3 & 20.9 & -27.3 & 563.5 & 84.5 & 173.5 & 107.5 & 5.8 \\
\hline 468 & 1.4 & 25.6 & -30.9 & 435.0 & 44.0 & 144.2 & 96.8 & 5.5 \\
\hline 505 & 2.0 & 24.7 & -24.6 & 732.5 & 47.1 & 244.0 & 144.3 & 6.5 \\
\hline 519 & 2.8 & 25.8 & -22.3 & 588.0 & 88.6 & 195.9 & 110.2 & 6.2 \\
\hline 620 & 3.5 & 25.8 & -19.2 & 1410.0 & 200.0 & 214.2 & 150.6 & 5.9 \\
\hline 675 & 3.7 & 20.9 & -22.9 & 1228.5 & 97.0 & 164.9 & 126.4 & 5.4 \\
\hline 710 & 4.4 & 23.6 & -21.6 & 1452.6 & 115.8 & 179.3 & 141.4 & 5.8 \\
\hline 745 & 4.6 & 24.4 & -18.4 & 1801.9 & 124.8 & 225.5 & 168.9 & 6.0 \\
\hline 772 & 4.5 & 25.0 & -19.1 & 1644.8 & 111.3 & 224.1 & 177.1 & 5.6 \\
\hline 815 & 4.8 & 19.1 & -16.9 & 1588.6 & 145.9 & 246.2 & 190.4 & 5.8 \\
\hline 907 & 3.6 & 24.5 & -20.6 & 1117.3 & 75.6 & 198.1 & 155.0 & 5.7 \\
\hline 923 & 4.1 & 22.5 & -19.8 & 1372.6 & 100.5 & 233.2 & 177.4 & 6.0 \\
\hline 985 & 4.7 & 20.9 & -18.9 & 1116.9 & 94.7 & 227.2 & 165.5 & 6.0 \\
\hline 990 & 4.4 & 22.4 & -17.5 & 1074.3 & 71.9 & 225.9 & 163.9 & 6.2 \\
\hline
\end{tabular}


Table 2. Descriptive statistics of stations data

\begin{tabular}{llllllll}
\hline Component & Mean & Median & Minimum & Maximum & Std.Dev. & Skewness & Kurtosis \\
\hline $\mathrm{t}$ & 3.5 & 3.6 & 1.4 & 4.8 & 0.979 & -0.476 & -0.706 \\
$\mathrm{txx}$ & 20.9 & 23.6 & -22.5 & 25.8 & 10.987 & -4.036 & 16.750 \\
$\mathrm{tnn}$ & -18.9 & -19.8 & -30.9 & 25.0 & 10.607 & 3.782 & 16.400 \\
$\mathrm{r}$ & 1023.9 & 1095.6 & 435.0 & 1801.9 & 414.397 & 0.188 & -1.096 \\
$\mathrm{rx}$ & 88.4 & 88.2 & 42.3 & 200.0 & 37.940 & 1.168 & 2.253 \\
$\mathrm{~d}$ _r $>0.1$ & 205.9 & 206.2 & 144.2 & 259.7 & 31.640 & -0.118 & -1.003 \\
$\mathrm{~d}$ _r $>=1.0$ & 145.0 & 147.6 & 96.8 & 190.4 & 28.171 & -0.197 & -1.158 \\
$\mathrm{n}$ & 6.0 & 6.0 & 5.4 & 6.7 & 0.338 & 0.110 & -0.462
\end{tabular}

\section{Results}

\section{Homoclimate of Iceland stations}

Correlation analysis shows the expected high correlations between the highest maximum temperature and the lowest minimum temperature. Another statistically significant correlation is between the mean number of days with precipitation $(0.1 \mathrm{~mm}$ or more $)$ and the mean number of days with precipitation (1.0 $\mathrm{mm}$ or more).

For our study, we apply joining (tree clustering) Ward's method. This method is distinct from all other methods because it uses an analysis of variance approach to evaluate the distances between clusters.
This method attempts to minimize the sum of squares of any two (hypothetical) clusters that can be formed at each step. Refer to Ward (1963) for details concerning this method. In general, this method is regarded as very efficient; however, it tends to create clusters of small size.

Euclidean distance measure and City-block (Manhattan) distance are used:

$$
\begin{aligned}
& \text { Euclidean distance }(x, y)=\left\{\sum i\left(x_{i}-y_{i}\right) 2\right\}^{1 / 2} \\
& \text { City-block distance }=\frac{1}{m} \sum_{j=1}^{m}\left(\frac{\left|x_{1 j}-x_{2 j}\right|}{x_{1 j}+x_{2 j}}\right)
\end{aligned}
$$

The development of the clustering procedure and its application to meteorological data from the station in Iceland provides some insight into the

\begin{tabular}{|c|c|c|c|c|c|c|c|c|}
\hline Component & $\mathbf{t}$ & $\operatorname{txx}$ & $\operatorname{tnn}$ & $\mathbf{r}$ & $\mathbf{r x}$ & d_r $>>0.1$ & d_r $r>=1.0$ & $\mathbf{n}$ \\
\hline$t$ & 1.000 & 0.225 & -0.034 & 0.716 & 0.484 & 0.280 & 0.593 & -0.403 \\
\hline txx & 0.225 & 1.000 & -0.965 & 0.312 & 0.267 & 0.245 & 0.212 & -0.379 \\
\hline tnn & -0.034 & -0.965 & 1.000 & -0.182 & -0.133 & -0.173 & -0.104 & 0.356 \\
\hline $\mathrm{r}$ & 0.716 & 0.312 & -0.182 & 1.000 & 0.756 & 0.552 & 0.823 & -0.287 \\
\hline rx & 0.484 & 0.267 & -0.133 & 0.756 & 1.000 & 0.318 & 0.488 & -0.230 \\
\hline $\mathrm{d} r>0.1$ & 0.280 & 0.245 & -0.173 & 0.552 & 0.318 & 1.000 & 0.840 & 0.346 \\
\hline $\mathrm{d} \mathrm{r}>=1.0$ & 0.593 & 0.212 & -0.104 & 0.823 & 0.488 & 0.840 & 1.000 & 0.025 \\
\hline $\mathrm{n}$ & -0.403 & -0.379 & 0.356 & -0.287 & -0.230 & 0.346 & 0.025 & 1.000 \\
\hline
\end{tabular}

Table 3. Correlation table 


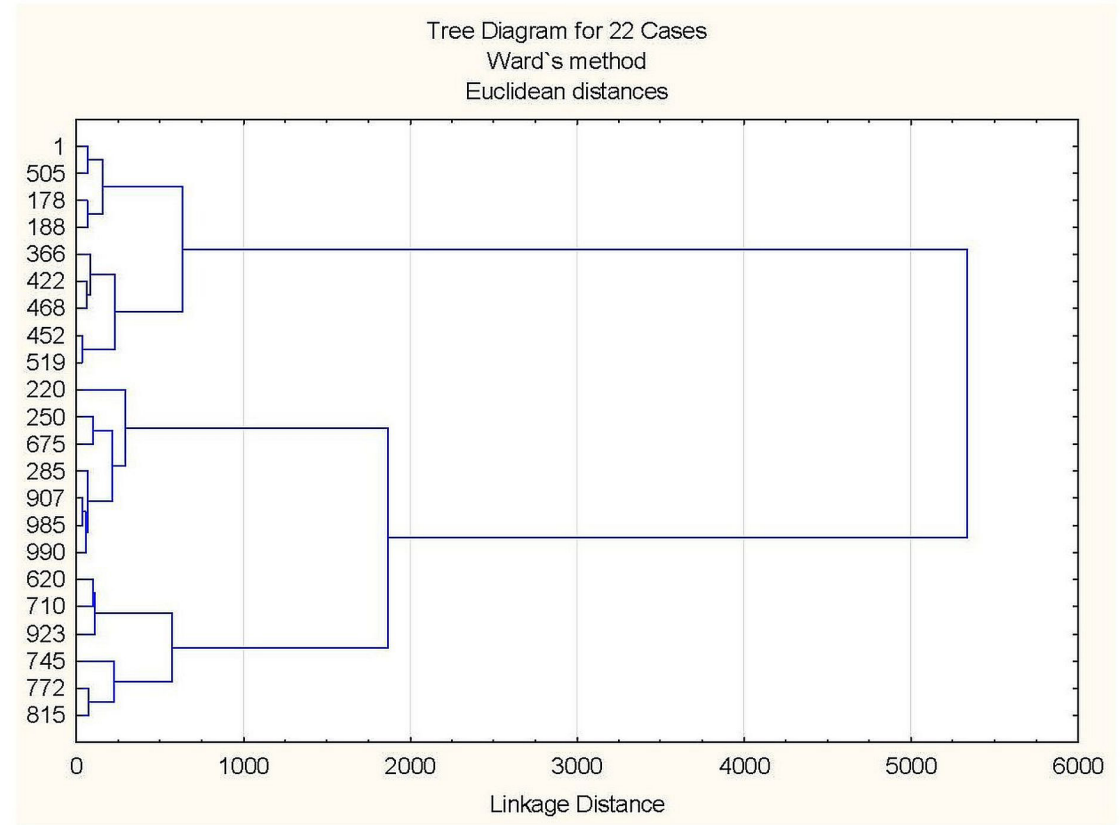

Fig. 1. Graphical presentation of results from the cluster analysis (1).

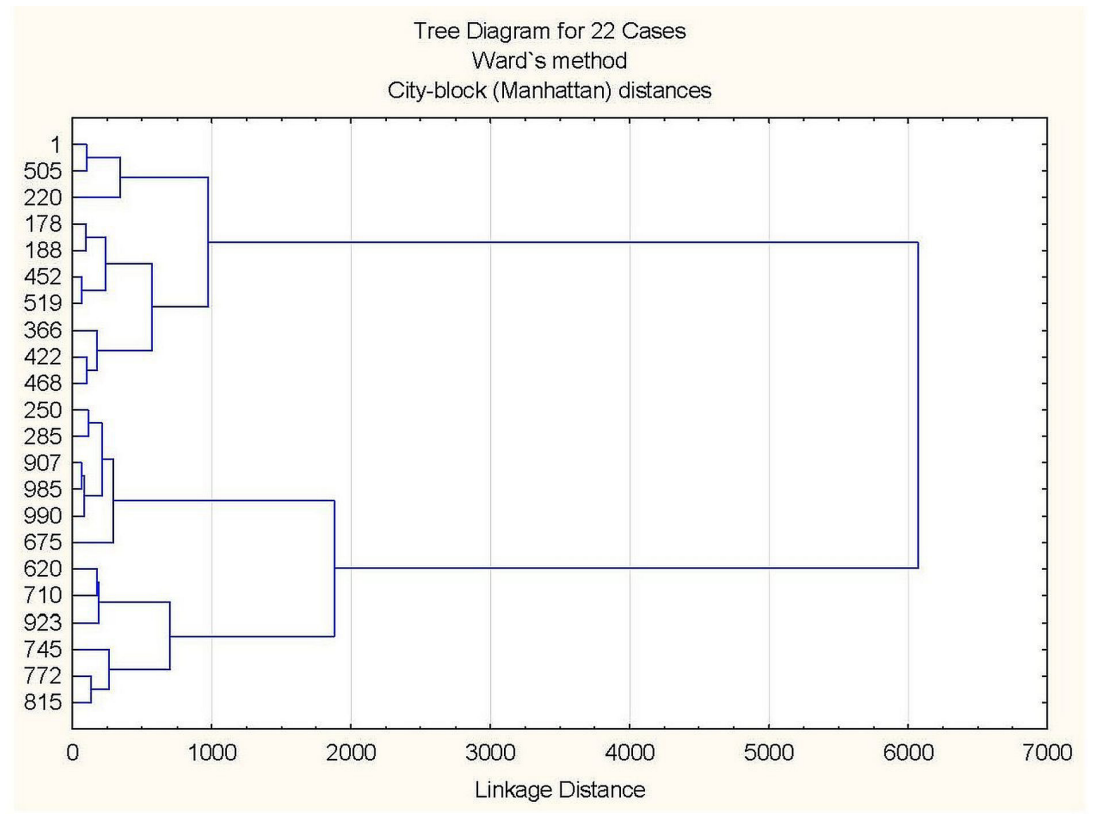

Fig. 2. Graphical presentation of results from the cluster analysis (2).

number and position of observation stations that are necessary to monitor adequately the climate of Iceland. The final result consists of three clusters, which combine stations with similar homoclimate. They can clearly be displayed on one map of the country (see Fig. 3). 


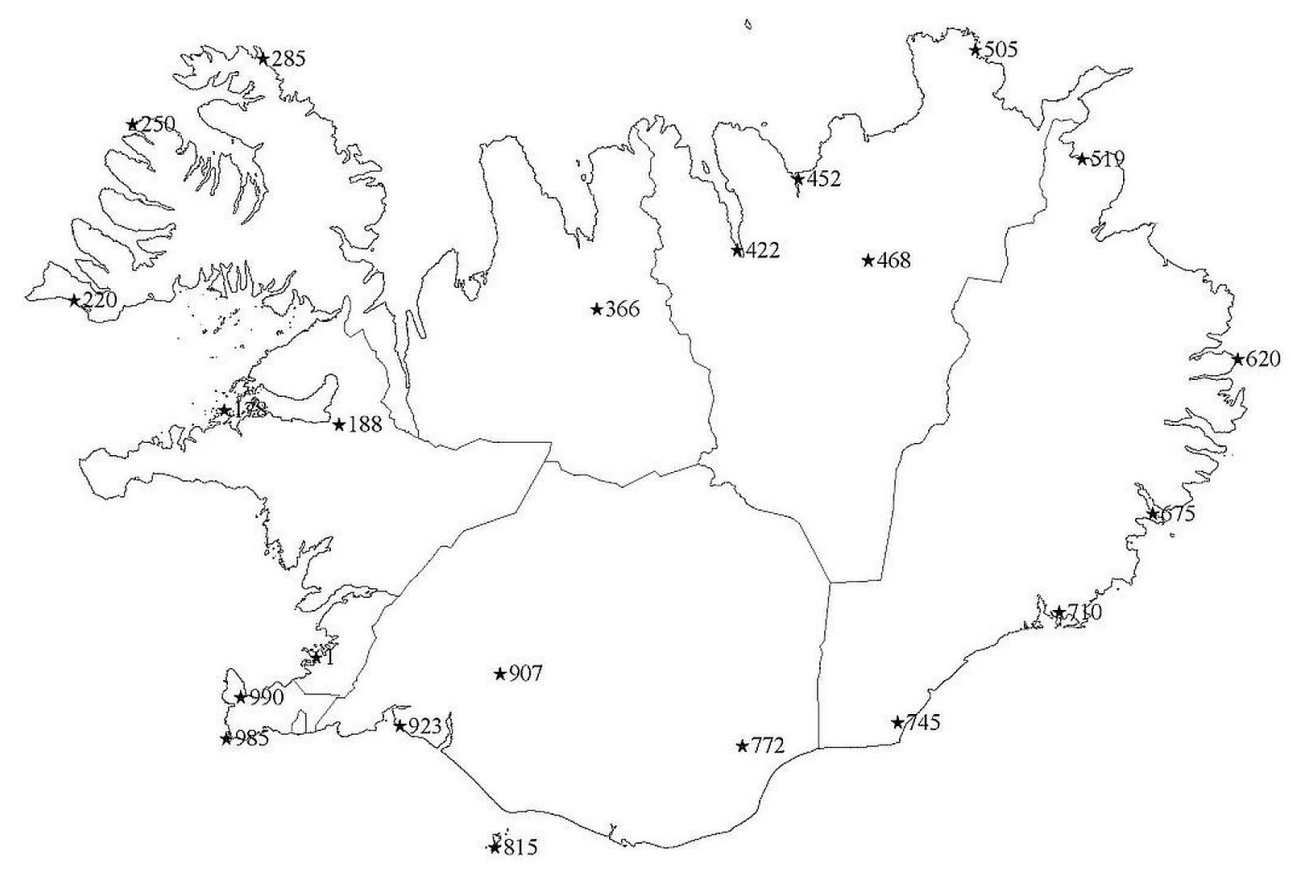

Fig. 3. Location of 22 meteorological stations.

Cluster 1 contains 9 cases - locations along the Western coast and Northern part of the country: 1, $178,188,366,422,452,468,505$ and 519.

Cluster 2 contains 7 cases - locations from Westfjords and Southern Peninsula: 220, 250, 285, 675, 907, 985 and 990.

Cluster 3 contains 6 cases - locations from Eastern and South coast: 620, 710, 745, 772, 815 and 923.

\section{Methods}

\section{Homoclime of Iceland and other Northern countries}

We think that in solving different problems in climatology, transfer of technology in agricultural practice to given areas and evaluation of bioclimatic resources, it is good to know areas or regions, which possess similar climates. This puts the task of making a comparison of the climate in Iceland and that of other Northern countries.
Important factors defining the climate and the growth and development of crops during the vegetation period are the average daily temperatures and the amount of precipitation during the year. For this purpose data from Finland, Sweden, Norway, and USA state Alaska, compared with the data for Iceland were used.

Our analysis is based on the WorldClim version 2.1 climate data for 1970-2000 (Fick and Hijmans 2017). This version was released in January 2020. There are monthly climate data for minimum, mean, and maximum temperature, precipitation, solar radiation, wind speed, water vapor pressure, and total precipitation. There are also 19 "bioclimatic" variables. The data is available at the four spatial resolutions, between 30 seconds $\left(\sim 1 \mathrm{~km}^{2}\right)$ to 10 minutes $\left(\sim 340 \mathrm{~km}^{2}\right)$. Each download is a "zip" file containing 12 GeoTiff (.tif) files, one for each month of the year (January is 1; December is 12). We are using data with a resolution of 5 minutes.

Processing of the geographic data passed several stages. At first GeoTiff images were converted to CSV tables by the QGis-16 system. Since the 
resulting tables have a number of rows exceeding the allowable in Excel (1048576 rows), it was necessary to use specialized software Delimit 4.1 (2019), which allows you to work with tables with more than 9 million rows. With its help, the data on the temperatures and precipitations in the separate territories were filtered.

The areas for consideration from different countries (Longitude, Latitude) are:

Iceland

Finland

Sweden

Norway

Alaska [-24.53 to $-13.50,63.38$ to 66.53$]$;

[19.40 to $31.50,59.90$ to 66.00$]$;

[11.00 to $24.00,55.00$ to 66.00$]$;

[4.60 to $15.00,58.00$ to 66.00$]$;

[-50.00 to $-10.00,55.00$ to 66.00$]$.

As you can see that the weather conditions are comparable because almost all areas are located between 55.00 and 66.00 latitude North. So individual climatic zones have not been considered. Using mean monthly data for mean temperature and precipitation, we can calculate the climatic similarity (homoclime) between two areas either by Euclidean distance, by City-block (Manhattan) distance, or by a Gower similarity measure (Gower 1971).

$$
\text { Gower similarity measure }=1-\frac{\left|x_{i k}-x_{j k}\right|}{r_{k}},
$$

where $r_{k}$ is the range of values for the $\mathrm{k}$-th variable.

Table 4 presents the results of the analysis, which reveal homoclime of the Northern countries closest to Iceland.

It is evident that the most similar climate to Iceland is those of Norway and Alaska.
Here is interesting to show the representation of similarity between countries from Europe and Asia to North America (McCarthy 2016). It can be seen (Fig. 4) that the countries of Northern Europe, to which Iceland belongs, have a similar climate with Alaska - the North-western state of America, which confirms our analysis and conclusions.

The climate maps show some countries that have what could be called a "climate twin".

\section{Discussion and conclusions}

Precise evaluation of climatically analogous regions in different countries of the world is important for solving several scientific and practical problems such as: detection of homoclime for the cropgrowing seasons, improvement of cropping practices and introduction of improved crop varieties from one region to another. The foregoing is an example of the use of numerical data analysis methods in the detection of similar homoclimates.

One of the conclusions from our study is that Iceland has a similar climate to Alaska and Norway. Its plausibility may be related to the facts about the distribution of glaciers in the Nordic countries in question. In our analysis only the relative share of the territories with glaciers in relation to the total territory of the indicated countries was considered (see Table 5). For the hydrothermal activity reliable data for all countries were not available and such analysis was not performed. Some figures about the land area are taken from the CIA (2020) and about

Table 4. Comparison of Iceland with the most similar Northern countries

\begin{tabular}{lcccc}
\hline \multirow{2}{*}{ State } & Mean values & \multicolumn{3}{c}{ Median values } \\
\cline { 2 - 5 } & Eucl. dist. & Manhat. dist. & Eucl. dist. & Manhat. dist. \\
\hline Iceland & 0.00 & 0.0 & 0.00 & 0.0 \\
Finland & 4.30 & 12.7 & 4.51 & 15.5 \\
Sweden & 3.99 & 12.1 & 4.58 & 15.3 \\
Norway & 2.04 & 6.8 & 3.60 & 12.1 \\
Alaska & 2.52 & 8.2 & 2.80 & 8.6
\end{tabular}




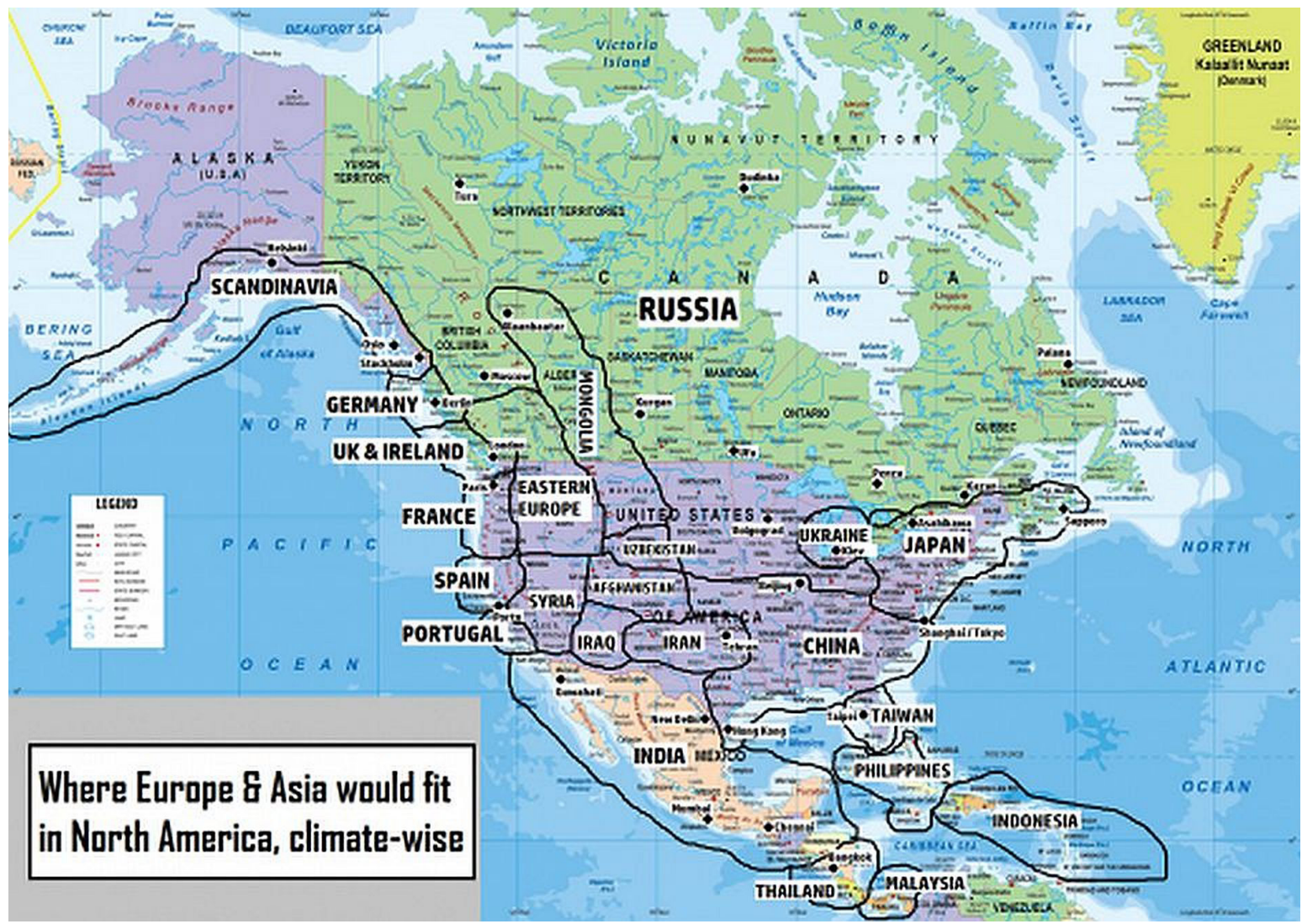

Fig. 4. A climate map comparison of USA, (McCarthy 2016).

glaciers area from the National Snow and Ice Data Center (WGMS 1999, updated 2012). The relative proximity of the percentages of the areas with glaciers once again confirms the similarity of the climate of Iceland with that of Norway and Alaska.
Future climate change will likely negatively affect crop production in southern countries, while positive trends are evident in some northern regions. Finland, Sweden, Norway, Iceland and Alaska will reconsider the list of crops to grow in the future decades.

Table 5. Comparison of areas with glaciers

\begin{tabular}{lccc}
\hline Territory & Land Area $\mathbf{~ k m}^{2}$ & Glaciers Area $\mathbf{~ k m}^{2}$ & \% of Territory \\
\hline Iceland & 102775 & 11058.20 & 10.76 \\
Finland & 303815 & 0.00 & 0.00 \\
Sweden & 410335 & 264.48 & 0.06 \\
Norway & 304282 & 51591.50 & 16.96 \\
Alaska & 1481346 & 88059.70 & 5.94
\end{tabular}


Results from this study are related to the territory of Iceland, but the approach to classify meteorological stations according to similar homoclimate and reveal homoclime in selected territories is applicable everywhere in the world.

\section{Disclaimer}

The mention of trade names or commercial products is for the information of the reader and does not constitute an endorsement or recommendation for use by the authors or their institutions. The Authors declare that there is no conflict of interest. This research received no specific grant from any funding agency, commercial or not-forprofit sectors.

\section{References}

- CIA. 2020. The World Factbook. https://www.cia.gov/library/ publications/the-world-factbook/geos/us.html. Accessed Dec. 2020.

- Delimit. 2019. Delimit 4.1 - User Guide and Help Manual. http://delimitware.com/help.html. Accessed Aug. 2019.

- Einarsson, M.Á. 1984. Climate of Iceland, in H. van Loon (Ed.): World Survey of Climatology: 15: Climates of the Oceans. Elsevier, Amsterdam, p. 673-697.

- Fick, S.E. and R.J. Hijmans. 2017. WorldClim 2: new $1 \mathrm{~km}$ spatial resolution climate surfaces for global land areas. International Journal of Climatology 37 (12): 4302-4315.

- Gower, J.C., 1971. A general coefficient of similarity and some of its properties. Biometrics, 27, 857-871.

- Guðjónsdóttir S. (Ed.) 2018. Iceland in figures 2018, Volume 23. Published by Statistics Iceland. ISBN 978-9979-770-58-9.

- Icelandic Met Office. 2020. Climatological data: 30 years average 1961-1990 for selected stations. https://en.vedur.is/ climatology/data/\#aa. Accessed Oct. 2020.

- Iglesias A., L. Garrote, S. Quiroga, M. Moneo. 2012. A regional comparison of the effects of climate change on agricultural crops in Europe. Climatic Change, 112(1), 29-46.

- Lader R., U.S. Bhatt, J.E.Walsh, T.S.Rupp, P.A. Bieniek. 2016. Two-Meter Temperature and Precipitation from Atmospheric Reanalysis Evaluated for Alaska. Journal of Applied Meteorology and Climatology, V. 55, 901-922. DOI: 10.1175/ JAMC-D-15-0162.1.

- Meigs, P. 1953. World distribution of arid and semi-arid homoclimates. In: Arid Zone Program, 1. Reviews of Research on Arid Land Hydrology. UNESCO, Paris, 203-210.
- McCarthy, A.M. 2016. Colorful climate comparison maps. https://www.lonelyplanet.com/news/2016/07/04/climatemaps-world-weather-australia/. Accessed Sept. 2020.

- Merriam-Webster Dictionary. Definition of Homoclime. https://www.merriam-webster.com/dictionary/homoclime/. Accessed Sept. 2020.

- Nojarov, P., 2017. Genetic climatic regionalization of the Balkan Peninsula using cluster analysis. J. Geogr. Sci., 27, 1, 43-61. https://doi.org/10.1007/s11442-017-1363-y.

- Peltonen-Sainio, P. 2012. Crop production in a northern climate. In: Building resilience for adaptation to climate change in the agriculture sector. Proceedings of a Joint FAO/ OECD Workshop, 23-24 April 2012, 183-216.

- Porter J.R., L. Xie, A.J. Challinor, K. Cochrane, S.M. Howden, M.M. Iqbal, D.B. Lobell, and M.I. Travasso. 2014: Food security and food production systems. In: Climate Change 2014: Impacts, Adaptation, and Vulnerability. Part A: Global and Sectoral Aspects. Contribution of Working Group II to the Fifth Assessment Report of the Intergovernmental Panel on Climate Change [Field, C.B., V.R. Barros, D.J. Dokken, K.J. Mach, M.D. Mastrandrea, T.E. Bilir, M. Chatterjee, K.L. Ebi, Y.O. Estrada, R.C. Genova, B. Girma, E.S. Kissel, A.N. Levy, S. MacCracken, P.R. Mastrandrea, and L.L. White (eds.)]. Cambridge University Press, Cambridge, UK and New York, USA, pp. 485-533.

- Prescott, J.A. 1938. The climate of tropical Australia in relation to possible agricultural occupation. Trans. Roy. Soc. S. Australia, 67, 312-318. 
Prescott, J.A., J.A. Collins and G.R. Shirpurkar, 1952. The comparative climatology of Australia and Argentina. Geograph. Rev., 42: 118-133.

- Russel, J.S. 1982. Selection of homoclimates based on comparisons with single stations and using monthly rainfall and temperature data. Agr. Meteorology, 26, 179-194.

- Russel, J.S., A.W. Moore. 1970. Detecting of Homoclimates by numerical analysis with reference to the Brigalow region (Eastern Australia). Agr. Meteorology, 7, 455-479.

- Sadovski, A.N. 2019. Detection of Similar Homoclimates by Numerical Analysis. Bulgarian Journal of Soil Science, Vol. 4, Issue 1, 69-75. Sofia. DOI: https://doi.org/10.5281/ zenodo.3250857.
- Sigurdsson, F.H. and M.Å. Einarsson. 1979. GREINARGERD UM VEDURFAR VEGNA SKIPULAGS ÍSLANDS OG SETBERGSLANDS f HAFNARFIRDI. Reykjavik, 27 pp.

- Stanev, S., M. Kyuchukova, S. Lingova. 1991. The climate of Bulgaria. Sofia, IMH-BAS Press, 500. (in Bulgarian).

- Statistics Iceland. 2015. Landshagir 2015 Statistical Yearbook of Iceland 2015. Editor Svava Guðjónsdóttir, 444 pp. ISBN 978-9979-770-55-8.

- Ward, J. H. 1963. Hierarchical grouping to optimize an objective function. J. Amer. Stat. Assoc., 58, 236.

- WGMS. 1999, updated in 2012. World Glacier Inventory, Version 1. Boulder, Colorado USA. NSIDC: National Snow and Ice Data Center. DOI: https://doi.org/10.7265/N5/ NSIDC-WGI-2012-02. Date Accessed 05.12.2020. 